\title{
Do Not Attempt Resuscitation Order
}

\author{
F.J. DE LATORRE
}

Since 1974, when the first policies about 'do not attempt resuscitation' orders were published [1], the decision not to resuscitate patients in cardiac arrest has been a controversial issue in medical practice. For this reason, the 'do not attempt resuscitation' order is, perhaps, the directive and the decision to withhold medical treatment with the widest bibliography. In this review, in accordance with the 2000 Guidelines for Cardiopulmonary Resuscitation [2], I will use the term 'do not attempt resuscitation (DNAR)' instead of the more popular 'do not resuscitate (DNR)'. The first sentence indicates more clearly the decision to take, because the success of a resuscitation is not always guaranteed.

In the practice of resuscitation, it has been accepted for many years that when a person has suffered a sudden cardiac arrest, resuscitation manoeuvres should always be started 'except in narrowly defined circumstances' [3]. This concept has not changed in the current guidelines [2,4]. This concept is unique in the practice of medicine, and it is based on the facts that it is an emergency and also a benefit for the patient [5]. The rationale lies in the belief that life is precious and that resuscitation will be successful. However, the latter is not true and the rate of survival ranges between $15-25 \%$ [6] and many of the initially resuscitated patients have residual impairment if the resuscitation is not completely achieved [7], thus prolonging the suffering of both patients and relatives [8]. Today we know well that all attempts at resuscitation should be previously assessed and agreed with the patient or relative, if this is possible [9].

\section{What Are the Real Possibilities of Success in Resuscitation?}

The rationale for always starting cardiopulmonary resuscitation (CPR) manoeuvres in a cardiac arrest in patients without a poor prognosis due to 
underlying diseases is based on the good results in many individual patients, with both good neurological recovery and quality of life. However, the rate of survival after a cardiac arrest has been not higher than $25 \%$ in the better results [10] and the average standard rate is $6 \%$ of survivors emerging from an out-of-hospital cardiac arrest [11] and it may be as lower as $1.4 \%$ in New York City [12]. In hospital cardiac arrests the current survival after resuscitation to hospital discharge is $17 \%$ in the USA, according to the National Registry of Cardiopulmonary Resuscitation [13].

In recent years, an improvement in positive outcome after cardiac arrest has been observed in some special sites, as in the casinos of Las Vegas, with the use of automated external defibrillators by trained non-healthcare personnel, with a $53 \%$ of survival to discharge from the hospital [14]. A significant increase in survival has been observed in the PAD Trial [15] with the use of automated external defibrillators in public access defibrillator programmes in comparison with standard resuscitation [16]. The functional state of survival patients in these series are good. The quality of life and the neurological state of the majority of long-term survivals are similar to the general population of the same age, as was observed in a group of 200 out-ofhospital cardiac arrest cases with ventricular fibrillation, with a survival rate to discharge of $42 \%$ [17].

In this context, it seems that the statement that resuscitation manoeuvres should always be started in a person who has suffered a sudden cardiac arrest are still applicable [2], unless a DNAR order had been dictated due to the poor recovery possibilities of the patient or that the patient himself/herself or his/her surrogate had given an advanced directive against the move CPR [8].

However, some voices have a different opinion based on the fact that many resuscitation survivors have permanent neurological disability [7] and suggest that resuscitation manoeuvres should not be initiated without a prior informed consent from the patient in which he/she specifically authorises resuscitation in the case of cardiac arrest, to avoid a heavy burden on the family and society in the form of a patient without hope [18]. As is natural, this proposal has been contested because it implies denying the possibility of survival to some patients, mainly favouring those who suffer a cardiac arrest with some particular circumstances which predispose them to a higher chance of success and a low likelihood of neurological impairment [19].

\section{Do Not Attempt Resuscitation Order: Ethical or Legal Issue?}

Although it is important to analyse the legal aspects, they can differ from one country to another and may not be clearly defined in their legal regulations, 
as is the case in Spain and in most European countries [4]. However, the ethical principles are accepted worldwide and they give us a more global guide $[4,9]$.

\section{The Patient's Autonomy to Decide}

Until a few years ago the decision of withholding cardiopulmonary resuscitation was a clinical decision of those in charge of the patient. However, since the Patient Self-Autodetermination Act was promulgated in December 1991, after its approval in the USA Supreme Court in June 25 of 1990, the patients or their surrogates have an important role in taking decisions in the patient's end of life. The Act recognises the right to give priority to the patient's wishes in order to preserve their personal freedom in taking medical decisions. However, the implementation of the patient's autonomy for taking medical decisions has been different from one country to another, due to cultural, religious and sociological reasons [8]. Although the final decisions should obviously be made by the physician in charge, after consulting the patient and the relatives [20], there are, however, numerous factors that influence the patient's decision.

The main factor in taking the decision to accept a DNAR order for the patients is the quality of life after discharge. If it may be restored to the previous level, $90 \%$ of the patients wanted resuscitation to be performed, while only a $16 \%$ wanted CPR if the possibilities for recovery were poor and only $6 \%$ if they would remain in vegetative state [21]. The diagnosis, the age (being older), being more functionally impaired and the patient's anticipation of a worse prognosis are also important factors [22]. The burden of treatment that would be needed to return to current health are also important, but the likelihood of a functional and, even more, a cognitive impairment, are the most important factors that influence the treatment preferences of the seriously ill older persons [23]. Race plays also a role in the patient's decision. In the USA, Hispanics and black patients want to prolong their lives and have a lower rate of DNAR orders than non-Hispanic white patients, regardless of their disease and prognosis [24-25].

Health economics and the way that health care is covered in different countries may also influence a patient's decision to refuse resuscitation. In the USA, treatment decisions are often taken under the influence of insurance coverage rather than the real desires of the patients [26]. Moreover, the cultural context may have an important role in the patient autonomy. In Japan, the family and the physicians' role in ethical decisions at the end of life are greater than that of the patients [27].

Physicians' opinions may differ when faced with the same situation and 
the physicians' attitudes concerning life support may influence the patient's and relatives' decisions. The medical speciality and the years of experience influence the opinions regarding DNAR orders [28]. Not only the physicians themselves, but the type of hospital where they work influence the patient's decision. In the SUPPORT study, the hospital site was an independent factor associated with patient CPR preferences [22]. The lack of training in communication and in taking decisions at the end of life in the physician's medical education may produce patient insecurity at the moment of taking a decision regarding preferences for CPR [8]. Consensus protocols may assist for taking decisions in life-threatening situations by helping physicians to decide the treatment in these situations [29].

The approach that the decision of a DNAR order should be decided after discussion between the patients and their relatives and the responsible physician to know the patient's desires, is well accepted in USA, however, it is not totally implemented in other countries. In Europe, there is no well established culture of patient autonomy and the proposal to withhold or withdraw lifesupport measures is usually initiated by the physician in charge. In Spain this rate is as high as $92.9 \%$ [30]. This European 'paternalistic approach' by the physicians may indicate that the physician takes the unilateral decision not to perform CPR [31], as well as practice resuscitation manoeuvres in a patient without clear possibilities of a good outcome, without knowing the patient's wishes [32]. This conduct, however, is not uniform in different European countries. In 1999, the written DNAR orders were applied only by $8 \%$ of Italian physicians whereas in The Netherlands $91 \%$ of the physicians agreed on stating a DNAR order when indicated [33]. Due also to cultural and religious reasons, the physician's decision to perform an unsuccessful CPR may fluctuate from country to country in Europe between 5\% and 48\% [32].

On some occasions, the physician may even override a DNAR order [20]. This may happen, for instance, in iatrogenic cardiac arrest, especially when it is due to a physician's error $[19,34]$.

In some situations, the patients are not competent to take decisions or to express their wills. The ICU is one of the contexts where it is harder to determine patients' wishes. Less than $5 \%$ of ICU patients have the capacity to take a decision about their end-of-life care [35]. In these cases, relatives or surrogates are the physician's interlocutors to agree a DNAR order. In recent years, in order not to misinterpret the wishes of these patients, advanced directives have been introduced in many countries, such as living wills, and the nomination of selected surrogates, for notifying and discussing about patient endof-life decisions. However, these have proven to be of little help, mainly because their implementation has been very poor, at least in Europe. In Finland, in a recent study, only $3 \%$ of the residents in long-term care facilities have living wills [31]. In one Spanish region, Andalusia, with more than 6 mil- 
lion inhabitants, the Advanced Directive Register had only 252 subjects with living wills registered [36], two years after the Spanish law on patient autonomy and advanced directives had been published [37].

\section{Medical Futility in DNAR}

The decision of a DNAR order should be agreed between the patients and/or their relatives or surrogate and the physicians, but sometimes there is disagreement. When the patients or relatives demand full resuscitation and the physicians do not agree, the physicians usually base their opinion on the fact that CPR will be futile [5].

The definition of futility in resuscitation is not clear. In front of one identical theoretical clinical situation the physician's opinions regarding DNAR orders differ among different medical specialities and depend also on the years of experience [28]. Curtis et al. have found evidence of major misunderstandings of the concepts of both quantitative and qualitative futility [38]. Some recommendations have been proposed to help physicians to determine medical futility $[29,39]$. In recent years, some voices have claimed a better definition of futility in order to preserve the patient in the case of a unilateral physician decision, taking into account the inconsistency of the futility definition [40]. It has even considered that a unilateral DNAR order taken by an individual physician, without patient or relative agreement, may constitute malpractice and an uncertain legal position [5,9]. In the USA, the courts have not supported physicians' determinations of futility in these cases [5].

In order to guarantee the best benefit for the patient, an individual physician should never write a DNAR order without an active enquiry into the patient's desires, if they are aware. If they are not aware, the decision should only be taken after a discussion with their relatives or surrogates. In the case of dissent, a neutral process should be initiated in order to resolve the disagreement [41]. Seeking a second opinion may help to clarify the patient's prognosis to the family, or it may require an Ethical Committee consultation to reach a fair decision that would satisfy all [40]. Consensus panel guidelines may assist in taking the decision not to perform CPR [29]. In the recent Statement of the $5^{\text {th }}$ International Consensus Conference in Critical Care on Challenges in end-of-life care in the ICU, whilst recognising that the ultimate responsibility in taking the final decision is in the hands of the physician, recommends a 'shared decision' and an ethical consultation in case of conflict due to disagreement [35].

In some circumstances, futility has been proposed in order to ensure a hypothetical social justice: CPR in the wrong patient may prevent an appropriate treatment in a patient with more possibilities of survival for reasons of 
lack of resources $[4,42,43]$. However, the physician in his individual decision of proposing a DNAR order should never consider anything other than physiological condition of the patient and the possibilities of an outcome with a good quality of life [44].

\section{Should the Patient's Wishes Always Be Known for Performing CPR?}

In most clinical situations of cardiac arrest, the patient's opinion is not known. In out-of-hospital cardiac arrest, the first-responders and the emergency medical services in many of the cases are unaware of the underlying cause of the cardiac arrest. For many years, initiating CPR has been the standard practice in these situations. In a recent review, the main conclusion is that 'after 25 years of do-not-resuscitate orders, it remains reasonable to presume consent and attempt resuscitation for people who have an unexpected cardiopulmonary arrest or for whom resuscitation may have physiologic effect and for whom no information is available at the time as to their wishes' [8].

In others settings, as in hospitals, long-term care facilities, etc., patient's wishes should be more easily come by, as well as the underlying diseases and their prognosis. However, the patients seldom have the opportunity to give their opinion about an end-of-life decision and the physician responsible in most of the cases does not initiate a process to establish a DNAR order either, or indicate the procedures when faced with a cardiac arrest, when it occurs. The rate of written DNAR orders is very different from one country to another, with a wide range, but it is far from optimal even in patients with a high risk of mortality and poor chance of recovery from a cardiac arrest [22, 30, $32,33]$. Here, as well as in out-of-hospital cardiac arrests, guidelines, formal policies, etc, should be stated in order to guarantee the patient benefit, not only in terms of initial survival but also subsequent quality of life $[8,42,45]$.

\section{Conclusions}

Although autonomy is considered the primary ethical principle in a cardiac arrest situation, it remains difficult to apply. A cardiac arrest is always an emergency situation and the patient's desires are seldom stated beforehand. In this situation, the weight of the ethical principle of beneficence and non-maleficence is the most important [43]. The physicians are obliged in these situations to evaluate the real possibilities of the outcome of resuscitation in a particular patient, actively seek the wishes of the patient, relatives or surrogate, whenever possible. Ideally, the decision should be taken in 
advance, via a written DNAR order, in agreement with the patient or representatives, always bearing in mind that saving the patient's life is not always the main objective: this remains the restoration of the prior health status $[8$, $21,23,43]$.

\section{References}

1. American Heart Association (1974) Standards and guidelines for cardiopulmonary resuscitation (CPR) and emergency cardiac care (ECC): Medicolegal considerations and recommendations. JAMA 227(Suppl):864-866

2. American Heart Association in collaboration with International Liaison Committee on Resuscitation (2000) Guidelines 2000 for cardiopulmonary resuscitation and emergency cardiovascular care: International consensus on science. Part 2: Ethical aspects of CPR and ECC. Resuscitation 46:17-27

3. Emergency Cardiac Care Committee and Subcommittees, American Heart Association (1992) Guidelines for cardiopulmonary resuscitation and emergency cardiac care. Part VIII: Ethical consideration in resuscitation. JAMA 268:2282-2288

4. Anonymous (1988) Ethical principles in out-of-hospital cardiopulmonary resuscitation. In: Bossaert L (ed) European Resuscitation Council Guidelines for Resuscitation. Elsevier, Amsterdam, pp 206-209

5. Cotler MP (2000) The 'do not resuscitate' order; clinical and ethical rationale and implications. Med Law 19:623-633

6. Eisemberg MS (1990) Cardiac arrest and resuscitation: A tale of 29 cities. Ann Emerg Med 19:179-186

7. Roine RO, Kajaste S, Kaste M (1993) Neurophysiological sequelae of cardiac arrest. JAMA 269:237-242

8. Burns JP, Edwards J, Johnson J et al (2003) Do-not-resuscitate order after 25 years. Crit Care Med 31:1593-1595

9. Snider GL (1991) The do-not-resuscitate order. Ethical and legal imperative or medical decision? Am Rev Respir Dis 143:665-674

10. Eisemberg MS, Mengert T (2001) Cardiac resuscitation. N Engl J Med 344:1304-1313

11. Nichol G, Stiell IG, Laupacis A et al (1999) A cumulative meta-analysis of effectiveness of defibrillator-capable emergency medical services for victims of out-of-hospital cardiac arrest. Ann Emerg Med 34:517-525

12. The Pre-Hospital Arrest Survival Evaluation (PHASE) Study. Lombardi G, Gallagher J, Gennis P (1994) Outcome of out-of-hospital cardiac arrest in New York City. JAMA 271:678-683

13. Peberdy MA, Kaye W, Ornato JP et al (2003) Cardiopulmonary resuscitation of adults in the hospital: a report of 14720 cardiac arrests from the National Registry of Cardiopulmonary Resuscitation. Resuscitation 58:297-308

14. Valenzuela TD, Roe DJ, Nichol G et al (2000) Outcomes of rapid defibrillation by security officers after cardiac arrest in casinos. N Engl J Med 343:1206-1209

15. The PAD Trial Investigators (2003) The public access defibrillation (PAD) trial. Study design and rationale. Resuscitation 56:135-147

16. http://www.nih.gov/news/pr/nov2003/nhlbi-11.htm

17. Bunch TJ, White RD, Gersh BJ et al (2003) Long-term outcomes of out-of-hospital cardiac arrest after successful early defibrillation. N Engl J Med 348:2626-2633

18. Jaffe AS, Landau WM (1993) Death after death: The presumption of informed con- 
sent for cardiopulmonary resuscitation - ethical paradox and clinical conundrum. Neurology 43:2173-2178

19. Choudhry NK, Choudhry S, Singer PA (2003) CPR for patients labelled DNR: The role of the limited aggressive therapy order. Ann Intern Med 138:65-68

20. Karnik AM, Brook S (2002) End-of-life issues and do-not-resuscitate order. Who gives the order and what influences the decision? Chest 121:683-686

21. Frankl D, Oye RK, Bellamy PE (1989) Attitudes of hospitalised patients toward life support: a survey of 200 medical inpatients. Am J Med 86:645-648

22. Phillips RS, Wenger NS, Teno J et al (1996) Choices of seriously ill patients about cardiopulmonary resuscitation: correlates and outcomes. Am J Med 100:128-137

23. Fried TR, Bradley EH, Towle VR et al (2002) Understanding the treatment preferences of seriously ill patients. N Engl J Med 346:1061-1066

24. Caralis PV, Davis B, Wright $\mathrm{K}$ et al (1993) The influence of ethnicity and race on attitudes toward advanced directives, life-prolonging treatments and euthanasia. J Clin Ethics 4:155-165

25. Shepardson LB, Gordon HS, Ibrahim SA et al (1999) Racial variation in the use of do-not-resuscitate orders. J Gen Intern Med 14:15-20

26. Meier DE, Morrison RS (2002) Autonomy reconsidered. N Engl J Med 346:1087-1089

27. Ruhnke GW, Wilson SR, Akamatsu T et al (2000) Ethical decision making and patient autonomy. A comparison of physicians and patients in Japan and the United Sates. Chest 118:1172-1182

28. Kelly WF, Eliasson AH, Stocker DJ et al (2002) Do specialists differ on do-not-resuscitate decisions? Chest 121:957-963

29. Alexandrov AV, Pullicino PM, Meslin EM et al (1996) Agreement on disease specific criteria for do-not-resuscitate orders in acute stroke. Stroke 27:232-237

30. Esteban A, Gordo F, Solsona JF et al (2001) Withdrawing and withholding life support in the intensive care unit: a Spanish prospective multi-centre study. Intensive Care Med 27:1744-1749

31. Laakkonen ML, Finne-Soveri UH, Noro A et al (2004) Advanced orders to limit therapy in 67 long-term care facilities in Finland. Resuscitation 61:333-339

32. Sprung CL, Cohen SL, Sjokvist P et al (2003) End-of-life practices in European intensive care units. JAMA 290:790-797

33. Vincent JL (1999) Forgoing life support in western European intensive units: The results of an ethical questionnaire. Crit Care Med 27:1626-1633

34. Casarett DJ, Stocking CB, Siegler M (1999) Would physicians override a do-not-resuscitate order when a cardiac arrest is iatrogenic? J Gen Intern Med 14:35-38

35. Carlet J, Thijs LG, Antonelli M et al (2004) Challenges in the end-of-life care in the ICU. Statement of the 5th International Consensus Conference in Critical Care: Brussels, Belgium, April 2003. Intensive Care Med 30:770-784

36. Diario Medico. Viernes, 9 de Julio de 2004, p 10

37. Boletín Oficial del Estado. Ley 41/2002, de 14 de noviembre, básica reguladora de la autonomía del paciente y de derechos y obligaciones en materia de información y documentación clínica. BOE núm.274, 15 de noviembre 2002, pp 40126-40132

38. Curtis JR, Park DR, Krone MR et al (1995) Use of the medical futility rationale in do-not-attempt-resuscitation orders. JAMA 273:124-128

39. Doty WD, Walker RM (2000) Medical futility. Clin Cardiol 23(Suppl. II): II6-II16

40. Anonymous (1995) When is CPR futile? JAMA 273:156-158

41. Biegler P (2003) Should patient consent be required to write a do not resuscitate 
order? J Med Ethics 29:359-363

42. Doyal L, Wilsher D (1993) Withholding cardiopulmonary resuscitation: proposals for formal guidelines. BMJ 306:1593-1596

43. Mohr M, Kettler D (1997) Ethical aspects of resuscitation. Br J Anaesth 79:253-259

44. Waisel DB, Truog RD (1995) The cardiopulmonary resuscitation-not-indicated order: futility revised. Ann Intern Med 122:304-308

45. Anonymous (1998) The ethics of resuscitation in clinical practice. A statement on behalf of the European Resuscitation Council, 1994. In: Bossaert L (ed) European Resuscitation Council Guidelines for Resuscitation, Elsevier, Amsterdam, pp $210-217$ 